\title{
Drama in medicine
}

$\mathrm{D}$ r. Charles Hayter says there is nothing "radical" about his decision, back in the 1970s, to switch his primary career from drama to medicine. Actually, the two fields are remarkably similar, says the radiation oncologist at Credit Valley Hospital in Mississauga, Ont. Now, four decades later, Hayter has found a compromise that allows him to be both a physician and a playwright.

"The practice of medicine is quite theatrical," says Hayter. "We have our own language. We have our own style of dealing with people. We wear a particular uniform or costume."

There is one important difference, however, between Hayter's two careers: money. He would love to write plays full-time, but the financial rewards are meagre, so he continues to work three days a week as a radiation oncologist to support his play-writing habit.

Although Hayter shuns the adjective "radical" to describe his dual career track, he does attach the word to the late Toronto oncologist, Vera Peters, who championed the thenheretical view that lumpectomies, combined with radiation, could be just as successful in treating breast cancer as the more disfiguring mastectomies that were commonly performed in the 1970s. Peters also challenged the prevailing attitude that the physician, not the patient, should decide which treatment option to follow. Her theories were not widely accepted until the 1980s.

So radical was Peters that Hayter titled the play he wrote about her, Radical. It premieres July 4, 2014, at the Toronto Fringe Festival and runs intermittently until July 13.

Hayter was attracted to Peters' story because she is such an icon among radiation oncologists and her life was full of the essential ingredient for any good play: conflict — in this case, with

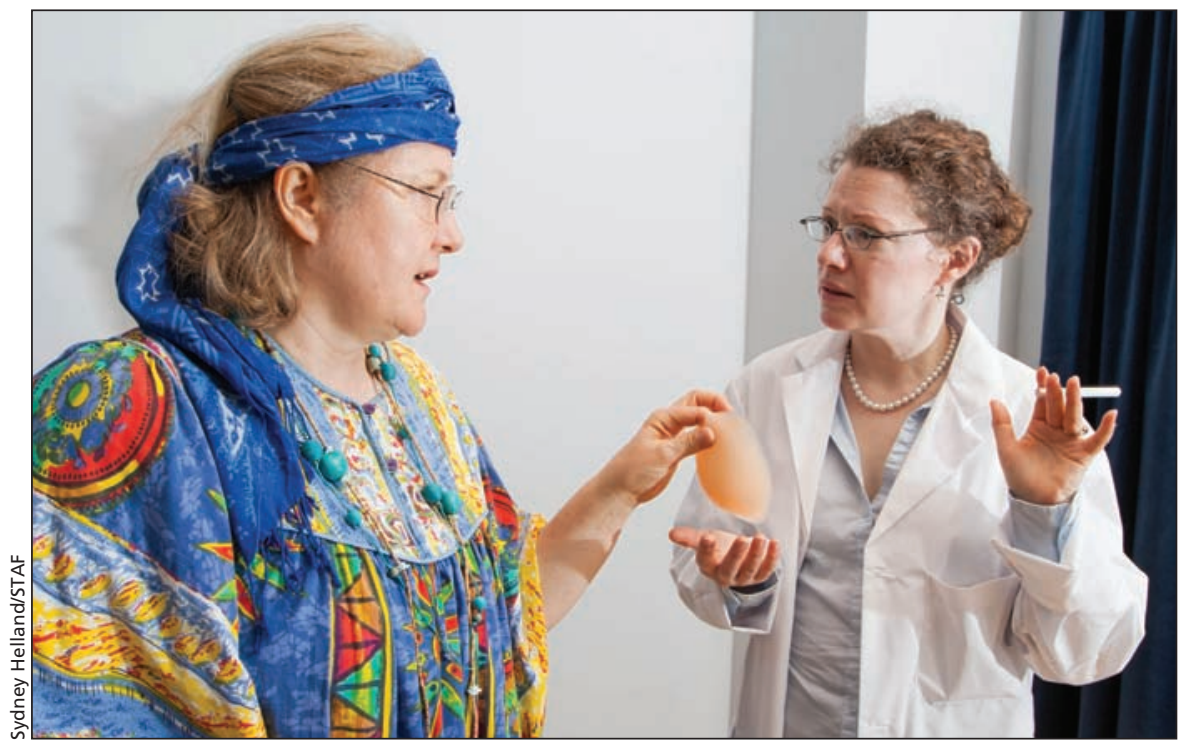

Rose Levine (played by Sheila Russell) has breast cancer, and her surgeons have recommended a mastectomy. Here, Rose seeks a second opinion from Dr. Vera Peters (played by Jane Smythe). Peters agrees that a mastectomy is the best choice and suggests that Rose wear a breast prosthesis. Rose disdainfully rejects this idea.

her mainly male peers who favoured radical mastectomies.

The plot of Radical sticks mostly to the historical record, but Hayter has condensed events and taken some dramatic licence to reach the heart of the story. "As Farley Mowat said: 'Never let the facts get in the way of the truth."

And, to be true to the historical record, many of the characters in Radi$c a l$, including Peters, "smoke" their way through the play. Lung cancer claimed Peters' life in 1993 at age 82.

"My work as an oncologist had a huge impact on Radical," says Hayter. "I confront the issues described in the play around medical decision-making and the patient's role in decision-making on a daily basis."

Fringe performances must not exceed an hour, so Hayter has abbreviated his original script. He hopes some day to mount the longer version of the play. Many modest productions launched at fringe festivals have eventually graduated to bigger and better things. The 1999 Toronto Fringe production of The Drowsy Chaperone evolved into a Tony Award-winning Broadway musical a few years later. In the case of Radical, Hayter is thinking more of Hollywood than Broadway. He wants to write a screenplay for an eventual movie.

"Most of the stuff I've written so far is based on medical history or medical themes, so I think my medical practice feeds into my writing," says Hayter. One much performed play written by Hayter is Lady in Waiting, about a doctor who is a drag queen. "Funny and fruitful," declared the Winnipeg Free Press in 2006. Another play, Eldorado Town - the Port Hope Play, which examined the benefits and harms of radium and uranium, was praised by The Globe and Mail in 2010 for its "interesting story" and "clever songs."

Humour is an integral part of every Hayter play. In Radical, the laughs come from the fictional character Rose, "a brassy, feisty feminist of the 
1970s." Rose is a foil to Vera, who is "always ladylike" and not a conventional feminist despite her efforts to empower female patients with cancer.

Hayter was born in England but later immigrated to Canada with his family. His grandfather and father were both physicians; his mother, a nurse. Initially, Hayter pursued his love of theatre, earning a master's degree in drama at the University of Calgary. He was contemplating a career as a theatre academic when medicine beckoned.

"Medicine was always in the background and what I intended to do." The actual switch in career paths came after a couple of life-changing events.

"Certainly a major [event] was my conversation with the Queen's [University] medical admissions officer, Dr. Dawson Einarson, who was enthusiastic about someone with an arts background entering medicine. Another was being witness to the birth of my daughter Rosalind and the wonder at the complexity of it all."

As a medical student, Hayter decided to specialize in radiation oncology after working at a cancer centre and being impressed by the staff.
"They were kind, compassionate people and I was just kind of naturally drawn to them. I thought this was something I would love to do."

Hayter went on to discover that choosing medicine did not have to mean abandoning drama. "The practice of medicine is theatrical," he says again. "I've always felt that, from the time I first started working as a doctor."

Paul Gessell

Art critic

Ottawa, Ont.

CMAJ 2014. DOI:10.1503/cmaj.140812

\section{POETRY}

\section{Shifting intimacies}

After all these years,

I'm showering with my wife

again.

The washing away of sweat and sleep.

Every morning

cleansing her body.

The running of water

and sunlight in the room.

The pain in her back grew

and the doctor said

"It's just arthritis."

She coughed and an x-ray

showed the white, white spots.

And then they all knew.

Her spine cracked and they all knew

there was nothing

but waiting and loving and pain and goodbyes.

The heat of breath released in night air.

After all these years, the shower pounding rhythmically against two bodies again.

\section{Marie O'Connor BSc MA}

Second-year medical student

Department of Medicine

University of British Columbia

Vancouver, BC

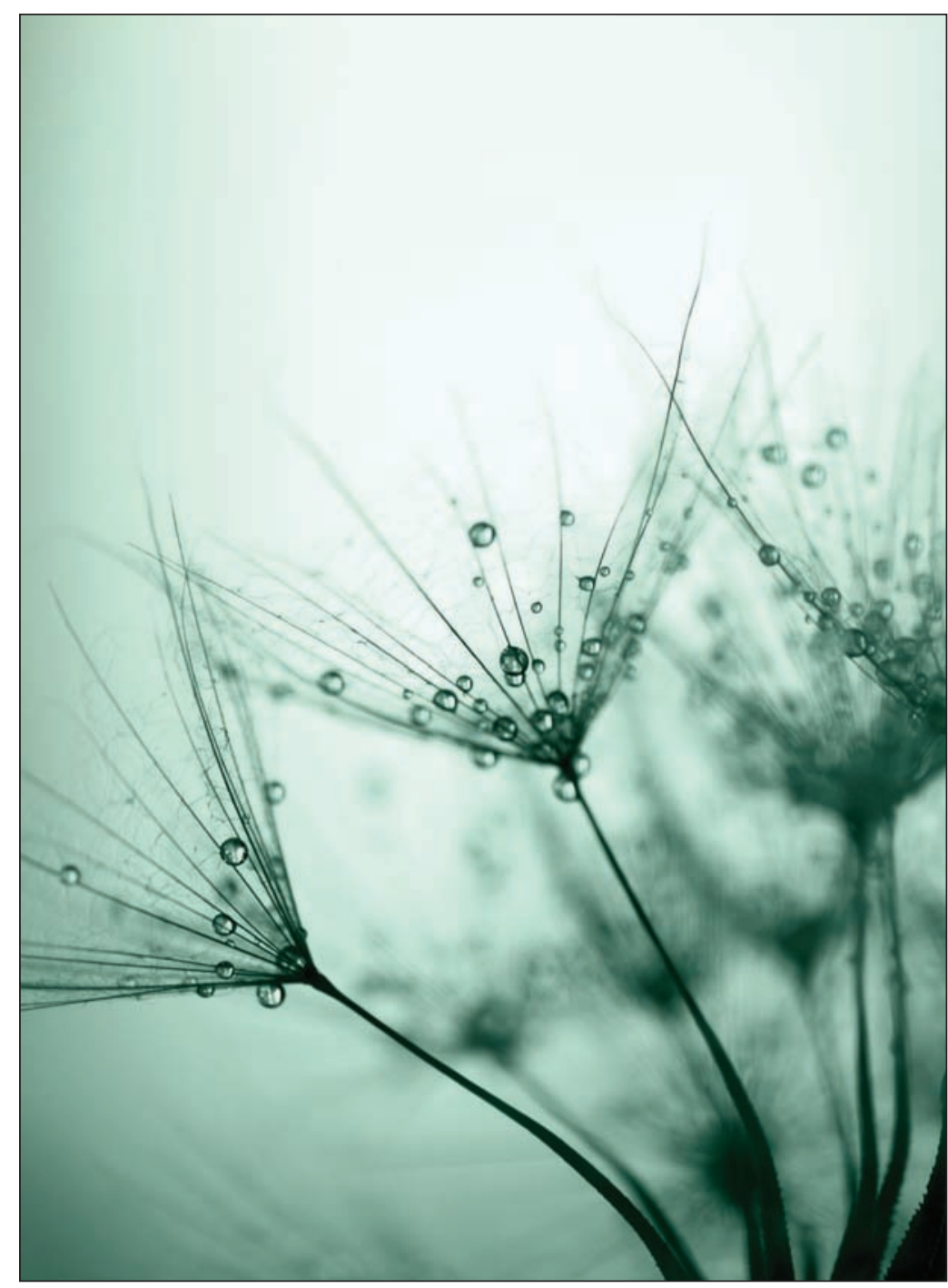

